\title{
Influence of atopy on exhaled nitric oxide in patients with stable asthma and rhinitis
}

\author{
Ch. Gratziou, M. Lignos, M. Dassiou, Ch. Roussos
}

Influence of atopy on exhaled nitric oxide in patients with stable asthma and rhinitis. Ch. Gratziou, M. Lignos, M. Dassiou, Ch. Roussos. (C)ERS Journals Ltd 1999.

ABSTRACT: The level of exhaled NO is increased in patients with allergic asthma and seasonal rhinitis. The aim of this study was to investigate the significance of atopy on NO production in the lower airways.

Measurements of exhaled NO were performed in 131 stable asthmatic patients with chronic mild asthma (95 atopics and 36 nonatopics), 72 patients with perennial rhinitis (57 atopics and 15 nonatopics) and 100 healthy controls (20 atopics and 80 nonatopics).

Patients with either asthma or rhinitis had higher exhaled NO values $(13.3 \& \pm 1.2$ parts per billion (ppb) and $11.7 \pm 1.1 \mathrm{ppb})$ than control subjects $(4.8 \pm 0.3 \mathrm{ppb}, \mathrm{p}<0.01)$. Exhaled NO levels were significantly higher in atopic asthmatics $(19 \pm 3.6 \mathrm{ppb}) \mathrm{com}$ pared with nonatopic patients $(5.6 \pm 0.8 \mathrm{ppb}, \mathrm{p}<0.001)$. Similar findings were observed in patients with rhinitis $(13.3 \pm 1.3 \mathrm{ppb}$ in atopics and $5.8 \pm 1.2 \mathrm{ppb}$ in nonatopics, $\mathbf{p}<\mathbf{0 . 0 0 1})$. No difference was found in NO levels between atopic and nonatopic control subjects $(4.8 \pm 0.8 \mathrm{ppb}$, and $4.5 \pm 0.3 \mathrm{ppb})$.

In summary, this study has shown that increased exhaled NO levels are detected only in atopic patients with asthma and/or rhinitis and not in nonatopic patients. These findings may suggest that it is rather the allergic nature of airways inflammation, which is mainly responsible for the higher NO production in the lower airways.

Eur Respir J 1999; 14: 897-901.

Endogenous NO is detectable in the exhaled air of normal individuals $[1,2]$. Several recent studies have demonstrated that the concentration of exhaled $\mathrm{NO}$ is increased in patients with inflammatory disorders of the airways, such as asthma [3-6], bronchiectasis [7] and upper or lower respiratory tract infection [8].

NO is generated from L-arginine by a family of enzymes, the nitric oxide synthases (NOS) [9]. Three distinct isoforms of human NOS have been cloned. The isoforms of endothelial and neuronal NOS are the constitutively expressed forms (cNOS) and changes in their activity regulate vascular tone, platelet activation and neurotransmission. The third isoform, the inducible NOS (iNOS), is only expressed after induction by certain inflammatory cytokines or by bacterial lipopolysaccharide by epithelial and infiltrative inflammatory cells $[9,10]$. iNOS has been localized in the airway and alveolar epithelium, the vascular endothelium, the smooth muscle and alveolar macrophages.

The lungs of healthy human subjects produce low but detectable levels of NO which presumably originate from cNOS activity. In asthmatic patients, the increase in exhaled NO may reflect increased expression of iNOS in response to inflammatory stimuli, such as cytokines [11]. Indeed, iNOS has been detected immunocytochemically in the airway epithelium of asthmatic patients but not in normal individuals [12]. Glucocorticoids, which control inflammation in asthmatic airways, have also been shown
Asthma and Allergy Center, Pulmonary and Critical Care Dept, Evgenidio Hospital, University of Athens, Greece.

\author{
Correspondence: Ch. Gratziou \\ Asthma and Allergy Center \\ Evgenidio Hospital \\ Papadiamantopoulou 20 \\ 11528 Ilisia \\ Athens \\ Greece \\ Fax: 3017242785
}

Keywords: Asthma

atopy

nitric oxide

rhinitis

Received: December 171998

Accepted after revision May 181999 to inhibit the expression of iNOS $[13,14]$ but not of cNOS [15]. Treatment with glucocorticosteroids decreases exhaled NO in a dose dependent manner in patients with stable asthma $[16,17]$ and in those suffering an acute exacerbation [18], but not in normal subjects.

Increased levels of nasal and exhaled NO have also been observed by some investigators in symptomatic allergic rhinitis, which may reflect an inflammation of the lower airways $[19,20]$. This increase can be modulated by local treatment with nasal steroids [21]. All these findings suggest that NO in exhaled air may be used as a marker of airway inflammation in asthma or rhinitis and as a useful index for monitoring anti-inflammatory treatment [22].

Most of these findings were, nevertheless, obtained in patients with allergic asthma or allergic rhinitis. The extent to which this is also the case for patients with nonatopic asthma remains thus far unclear. In addition, there are no studies investigating whether allergen sensitization and chronic allergen exposure may play a role in the NO production in the lower airways.

Therefore, in this study, the levels of exhaled NO in atopic and nonatopic subjects with stable asthma and/or rhinitis were investigated in order to assess whether there is any influence of atopy on the higher NO production in the lower airways and whether intrinsic asthma and nonallergic rhinitis are also accompanied by increased NO levels in the exhaled air. 


\section{Materials and methods}

\section{Study subjects}

The study was performed in 131 patients with chronic stable mild asthma, 72 patients with perennial rhinitis and 100 healthy control subjects. All subjects were clearly characterized as atopic or nonatopic, according to skin-prick test reactions to common allergens. The characteristics of the subjects are shown in table 1 .

The asthmatic patients had documented histories of mild asthma. All had $80 \%$ higher forced expiratory volume in one second (FEV1) values than predicted, and were stable for at least 2 weeks before the study. Fifty-seven patients had a history of asthma, and 74 were suffering from both asthma and rhinitis. At the time of the study, they had mild symptoms under treatment with $\beta_{2}$-agonists alone and they did not take inhaled steroids for the 4 weeks preceding the study.

The rhinitis group had no asthma-like symptoms in their history or during the study period. No patient was on treatment with nasal steroids.

The atopic control subjects had a history of atopic dermatitis but they had never had any respiratory symptoms of asthma or rhinitis. The nonatopic control subjects were healthy volunteers.

The mean age of the subjects in each study group did not differ significantly. At the time of the study, all patients had mild symptoms either from asthma and/or rhinitis, but no asthmatic was experiencing an exacerbation. No patient was under inhaled, nasal or oral steroid treatment for the 4 weeks preceding the study.

All study participants were nonsmokers and none of them reported upper or lower respiratory infection in the month preceding the study. The study protocol was approved by the hospital Ethics Committee.

\section{Study design}

At study entry, a detailed history was obtained in order to categorize the study groups. Atopy was assessed by skin-prick tests to 20 common allergens (as Dermatophilus pteronissus, D. farinae, mixed grasses I, grasses II, parietaria, weeds, timothy grass, flowers, mixed trees pollen I, mixed trees pollen II, olive, pine, cat hair, dog hair, mixed moulds, aspergilus, alternaria, candida, positive histamine control, negative saline control). The study subjects were characterized as atopic if they had a positive cutaneous reaction with $\mathrm{a} \geq 3 \mathrm{~mm}$ skin wheal response.

Table 1. - Characteristics of the study groups

\begin{tabular}{|c|c|c|c|c|c|c|}
\hline \multirow{2}{*}{ Study groups } & \multicolumn{2}{|c|}{ All subjects } & \multicolumn{2}{|c|}{ Atopics } & \multicolumn{2}{|c|}{ Nonatopics } \\
\hline & $\mathrm{n}$ & $\begin{array}{l}\text { Age } \\
\text { yrs }\end{array}$ & $\mathrm{n}$ & $\begin{array}{l}\text { Age } \\
\text { yrs }\end{array}$ & $\mathrm{n}$ & $\begin{array}{l}\text { Age } \\
\text { yrs }\end{array}$ \\
\hline All asthmatics & 131 & $33 \pm 14$ & 95 & $32 \pm 13$ & 36 & $37 \pm 14$ \\
\hline With asthma only & 57 & $33 \pm 15$ & 33 & $30 \pm 14$ & 24 & $38 \pm 17$ \\
\hline $\begin{array}{l}\text { With asthma plus } \\
\text { rhinitis }\end{array}$ & 74 & $33 \pm 12$ & 62 & $32 \pm 12$ & 12 & $34 \pm 9$ \\
\hline $\begin{array}{l}\text { Patients with } \\
\text { rhinitis only }\end{array}$ & 72 & $34 \pm 13$ & 57 & $34 \pm 13$ & 15 & $34 \pm 15$ \\
\hline Control subjects & 100 & $32 \pm 11$ & 20 & $30 \pm 12$ & 80 & $32 \pm 10$ \\
\hline
\end{tabular}

Data are presented as absolute number or as mean $\pm \mathrm{sD}$.
All control subjects and patients with rhinitis and/or asthma underwent measurements of nitric oxide levels in orally exhaled air. Exhaled NO was measured with three acceptable efforts, according to European Respiratory Society (ERS) guidelines [23].

None of the asthmatics who took part in the study were allowed to use short acting $\beta_{2}$-agonists for at least $6 \mathrm{~h}$ before the time of their visit to the lab where baseline spirometry, and methacholine provocation tests were performed after exhaled NO measurements.

\section{Methods}

Pulmonary functions and bronchial hyperreactivity tests. FEV1 and forced vital capacity (FVC) were measured using a water-sealed spirometer (Biomedin, Milan, Italy), the best of three manoeuvres being expressed as a percentage of the predicted value.

Bronchial hyperreactivity was assessed by a methacholine provocation test. The methacholine solution was nebulized with a hand-held nebulizer (Dosimeter MB3; MEFAR, Bovezzo, Italy) with an output of $100 \mu \mathrm{L}$. The concentration of methacholine started at $0.01-2 \mathrm{mg} \cdot \mathrm{mL}^{-1}$. The challenge test was continued up to the dose of methacholine that caused a $20 \%$ drop from baseline of FEV1 or until the maximum dose was inhaled. The cumulative dose causing a $20 \%$ fall in FEV1 (PD20) was calculated automatically by interpolation of the logarithmic dose response curve. Subjects were given two puffs of salbutamol $(200 \mu \mathrm{g})$ by a metered dose inhaler following the methacholine challenge.

Nitric oxide measurements. Exhaled NO was measured by a chemoluminescence analyzer (model LR2000; Logan research, Rochester, UK) sensitive to NO from $1-5,000$ parts per billion ( $\mathrm{ppb}$ ), which was designed for on-line recording of exhaled NO concentration. The analyzer was calibrated daily with $\mathrm{NO} / \mathrm{N}_{2}$ calibration gas containing $116 \mathrm{ppb}$. In addition to $\mathrm{NO}$, this analyzer measures $\mathrm{CO}_{2}$ concentration, pressure $(P)$ and volume $(V)$ in real time. The method used was the one described by KHARITONOv et al. [23] according to the ERS guidelines. The subjects exhaled slowly from total lung capacity (TLC) over 30-40 s through a mouthpiece against a mild resistance to exclude nasal contamination due to elevation of the soft palate against the oropharynx [24]. All subjects maintained an exhalation flow rate of 250 $\mathrm{mL} \cdot \mathrm{s}^{-1}$. NO was sampled from a side-arm attached to the mouthpiece. The mean value was taken from the point corresponding to the plateau of end-exhaled $\mathrm{CO}_{2}$ readings $\left(5-6 \% \mathrm{CO}_{2}\right)$ as representative of an alveolar sample. The results of the analysis were computed and graphically displayed on a plot of $\mathrm{NO}$ and $\mathrm{CO}_{2}$ concentrations, $P$, and flow $\left(V^{\prime}\right)$ against time.

\section{Statistical analysis}

Data of exhaled NO were expressed as mean \pm SEM. The mean value of three NO measurements was calculated for each subject. Comparison of NO values was performed using a two-way analysis of variance (ANOVA) between different groups using the Sheffe test. Correlations between 
Table 2. - Spirometric values and bronchial hyperreactivity levels in asthmatics and control subjects

\begin{tabular}{lccc}
\hline Asthmatics & $\begin{array}{c}\text { FEV1 } \\
\text { L }\end{array}$ & $\begin{array}{c}\text { FEV1 } \\
\% \text { pred }\end{array}$ & $\begin{array}{c}\text { PD20 } \\
\mathrm{mg} \cdot \mathrm{mL}^{-1}\end{array}$ \\
\hline Atopics $(\mathrm{n}=95)$ & $3.37 \pm 0.84$ & $102 \pm 13.2$ & $0.335 \pm 0.47$ \\
Nonatopics $(\mathrm{n}=36)$ & $2.84 \pm 0.79$ & $98.8 \pm 14.9$ & $0.363 \pm 0.55$ \\
Controls $(\mathrm{n}=100)$ & $3.41 \pm 0.91$ & $105 \pm 15.1$ & $\mathrm{ND}$ \\
\hline
\end{tabular}

Data are presented as mean \pm SD and for PD20 geometric mean \pm SD in doubling dose of methacholine. FEV 1 : forced expiratory volume in one second; PD20: provocative dose causing a $20 \%$ fall in FEV1.

PD20 and NO were determined using the Spearman rank correlation. Log transformed values of PD20 were used for analysis. Measurements of spirometry and bronchial hyperreactivity test in atopic and nonatopic asthmatics were compared using independent t-test. A p-value of $<0.05$ was considered significant.

\section{Results}

Regarding the spirometry and bronchial hyperreactivity tests, there were no differences between atopic and nonatopic asthmatics (table 2). Furthermore, no correlation was found between PD20 and $\mathrm{NO}$ values measured in asthmatics $(\mathrm{r}=-0.211, \mathrm{p}=0.1)$.

NO measurements have shown that patients with asthma had higher exhaled NO values $(13.3 \pm 1.2 \mathrm{ppb})$ than control subjects $(4.8 \pm 0.3 \mathrm{ppb}, \mathrm{p}<0.01)$. Increased exhaled NO levels were also found in patients with rhinitis $(11.7 \pm 1.1$ $\mathrm{ppb})$, compared with controls $(\mathrm{p}<0.01)$. There was no difference between the exhaled NO levels in asthmatics and in patients with rhinitis with or without asthma symptoms.

When exhaled NO levels were compared between atopic and nonatopic subjects in each group, statistically significant higher values were found in all atopic subjects (fig. 1). NO levels were $19 \pm 3.6 \mathrm{ppb}$ in atopic asthmatics compared with $5.6 \pm 0.8 \mathrm{ppb}$ in nonatopic asthmatics. Patients with concurrent asthma and rhinitis who were atopic had a mean NO value of $14.3 \pm 1.3 \mathrm{ppb}$, significantly higher than that found in nonatopic subjects of the same group $(7.5 \pm 3.8, \mathrm{p}<0.001)$.

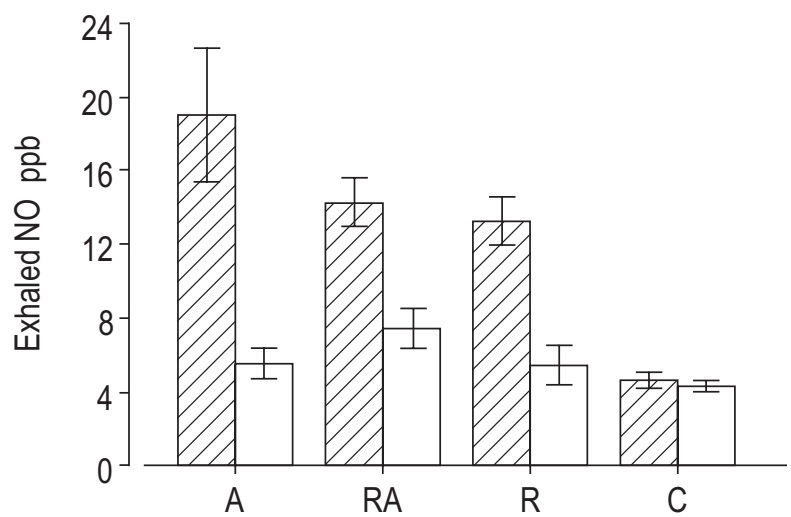

Fig. 1. - Mean \pm SEM values of exhaled NO in atopic $(\mathbb{Z})$ and nonatopic ( $\square$ ) subjects of each study group: A: asthmatic patients; RA: rhinitis and asthmatic patients; $\mathrm{R}$ : rhinitis patients; $\mathrm{C}$ : control subjects. ppb: parts per billion.
Similarly, patients with atopic rhinitis had a NO value of $13.3 \pm 1.3 \mathrm{ppb}$, significantly different from the $5.8 \pm 1.2 \mathrm{ppb}$ observed in patients with nonatopic rhinitis. Values of exhaled NO in nonatopic patients of either group did not differ significantly from those observed in control nonatopic subjects $(4.5 \pm 0.3 \mathrm{ppb})$. No differences were found in measured exhaled NO between atopic and nonatopic control subjects $(4.8 \pm 0.8 \mathrm{ppb}$ and $4.5 \pm 0.3 \mathrm{ppb}$, respectively).

\section{Discussion}

The major finding of the study is that increased exhaled NO levels have been observed only in atopic patients with stable asthma and/or rhinitis and not in nonatopic patients. Nonatopic asthmatics had statistically significant lower levels of NO detected in exhaled air, reaching the levels found in healthy subjects.

Increased NO levels have been considered to be a consistent finding in the orally exhaled air of asthmatics by several investigators [3-6]. However, in these previous studies, either atopic asthmatics were mainly included or the atopic condition was not defined and, consequently, no conclusion could be drawn about the exhaled NO levels in nonatopic asthmatics. Contrary to the current findings, PERsson et al. [4] found no difference in a small group of subjects in peak NO concentration between allergic and nonallergic asthmatics. However, the results of the present study were based on a large population and there was a clear distinction of atopic asthmatic patients and nonatopic asthmatic patients.

According to clinical symptoms, lung function measurements and bronchial hyperreactivity level, there was no difference in the severity of asthma between the atopic and nonatopic asthmatics from the study population. Thus, the theory that the differences found between the two groups, in exhaled NO were related to the severity of the disease can be excluded. Furthermore, in this study, there was no correlation between $\mathrm{NO}$ values and PD20 measured in asthmatics, suggesting that NO levels detected in exhaled air are not dependent on the degree of bronchial hyperreactivity.

Based on these findings, it could be hypothesized that it is the atopic condition per se that increases the NO production. However, no difference was found in NO detected in exhaled air between atopic and nonatopic healthy subjects. Thus, the results of the present study indicate that both atopy and upper or lower airways disease are conditions that may cause higher NO levels in exhaled air.

The findings of this study may suggest that it is the allergic nature of an inflammation of the airways that is mainly responsible for the higher NO production in the lower airways. Previous studies also provide evidence that allergic inflammation increases NO production. The experimental allergen challenge in asthmatic subjects causes a further increase of the already elevated exhaled NO concentration during the late asthmatic reaction [25]. Furthermore, increased exhaled and nasal NO were also found in subjects working in animal laboratories with early sensitization to animal allergens without clinical evidence of asthma, suggesting the importance of the role of allergen exposure and sensitization in the pathophysiology of NO production [26]. 
Undoubtedly, the important question is what the underlying mechanisms of the findings are. The experimental design does not allow the determination why solely atopic and not nonatopic patients with asthma and/or rhinitis under stable conditions have elevated exhaled NO levels.

It has been suggested that the increase of NO levels in atopic asthmatics and in patients with allergic rhinitis above those found in control subjects, may be consistent with the induction of iNOS (found in association with mucosal mast cells, eosinophils, and T-lymphocyte activation), that characterizes allergic rhinitis and asthma [27, 28]. An upregulation of expression of iNOS has been observed in bronchial biopsies in asthmatics [12,29] and immunocytochemical studies have also demonstrated expression of NOSs in human nasal mucosa [30]. According to the current results, it is tempting to speculate that the inflammatory milieu in the nonatopic patients does not induce iNOS efficiently, in contrast to the inflammatory milieu of atopic asthmatics. In fact, there is conflicting data regarding the differences in the immunopathogenesis of these two clinically distinct types of intrinsic and extrinsic asthma. Thus, there are some investigators who have found a lot of similarities in the pathophysiological profiles of the two types of the disease $[31,32]$, based on bronchoalveolar lavage or biopsy data, looking at T-cell phenotype, differential expression of cytokines, (such as interleukin (IL)-8, IL-5, IL-4, interferon gamma), and chemokines, (such as regulated on activation, normal T-cell expressed and secreted (RANTES), monocyte chemotactic peptide-3 (MCP-3)). On the other hand, there are studies which present differences in the pathophysiological inflammatory process [33-35] supporting the current theory. In addition, no studies have concentrated on the role of the epithelium in atopic and nonatopic asthma, which may be very important and thus requires investigation. Also, further investigation regarding iNOS expression in bronchial tissue in atopic and nonatopic patients with asthma or rhinitis is, of course, needed to clarify the pathophysiological mechanism that might explain the current findings.

It is important to clarify that this study refers to patients with asthma and/or rhinitis under stable conditions and not in acute exacerbations, where increased levels of NO have been shown by other investigators [18]. With that design, it was easier to investigate the influence of atopy on the NO production, as this was the only different parameter between the study subjects who were all under stable conditions. Acute exacerbations might be caused by different trigger factors such as allergens, viruses, or bacteria that may play a different role in the pathophysiological process responsible for the increase of NO. However, having as a baseline the findings of this study, which show the influence of atopy in NO measurements, it is very interesting to further investigate whether and how acute exacerbations of asthma or rhinitis may affect NO production in nonatopic subjects compared with atopic subjects. In addition, as increased NO levels are also observed in patients with bronchiectasis and upper or lower respiratory infections $[7,8]$, it is tempting to speculate that the mechanism of NO production may be multifactorial in different disease states and several causes or trigger factors may induce in a different manner the underlying pathophysiology.
In conclusion, the findings of this study suggest that NO mainly reflects the allergic origin of an inflammation of the airways, since it is elevated only in atopic patients. It is therefore suggested that atopy should be defined before using NO measurements as an index for monitoring airway inflammation, in patients with asthma and/or rhinitis under stable conditions. Clearly, further studies are needed to delineate the molecular mechanisms of this different NO production in the lower airways between atopic and nonatopic subjects with airway diseases like asthma or rhinitis.

\section{References}

1. Gustaffson LE, Leone AM, Persson M, Wiklund NP, Moncada S. Endogenous nitric oxide is present in the exhaled air of rabbits, guinea pigs and humans. Biochem Biophys Res Commun 1991; 181: 852-857.

2. Borland C, Cox Y, Higenbottam T. Measurement of exhaled nitric oxide in man. Thorax 1993; 4: 1160-1162.

3. Alving K, Weitzberg E, Lundberg JM. Increased amount of nitric oxide in exhaled air of asthmatics. Eur Respir $J$ 1993; 6: 1368-1370.

4. Persson $\mathrm{MG}$, Zetterstrom $\mathrm{O}$, Argenius $\mathrm{V}$, Ihre $\mathrm{E}$, Gustafsson LE. Single breath oxide measurements in asthmatic patientsand smokers. Lancet 1994; 343: 146147.

5. Kharitonov SA, Yates D, Robbins RA, Logan-Sinclair R, Shinebourne EA, Barnes PJ. Increased nitric oxide in exhaled air of asthmatic patients. Lancet 1994; 343: 133135.

6. Barnes P, Belvisi MG. Nitric oxide and lung disease. Thorax 1993; 4: 1034-1043.

7. Kharitonov SA, Wells AU, O'Connor BJ, Hansell DM, Cole PJ, Barnes PJ. Elevated levels of exhaled nitric oxide in bronchiectasis. Am J Respir Crit Care Med 1995; 151: 1889-1893.

8. Kharitonov SA, Yates DH, Barnes PJ. Increased nitric oxide in exhaled air of normal human subjects with upper respiratory tract infections. Eur Respir J 1995; 8: 295297.

9. Jorens PG, Vermeire PA, Herman AG. L-arginine dependent nitric oxide synthase: a new metabolic pathway in the lung and airways. Eur Respir $J$ 1993; 6: 258-266.

10. Gaston B, Drazen JM, Loscalzo J, Stamler JS. The biology of nitrogen oxides in the airways. Am J Respir Crit Care Med 1994; 149: 538-551.

11. Moncada S, Highs EA. The L-arginine nitric oxide pathway. N Engl J Med 1993; 329: 2002-2012.

12. Hamid Q, Springall DR, Riveros-Moreno V, et al. Induction of nitric oxide synthase in asthma. Lancet 1993; 342: $1510-1513$.

13. Di Rosa M, Radomski M, Carnuccio R, Moncada S. Glucocorticoids inhibit the induction of nitric oxide synthase in macrophages. Biochem Biophys Res Commun 1990; 172: 1246-1252.

14. Yates DH, Kharitonov SA, Robbins A, Thomas PS, Barnes PJ. Effect of a nitric oxide synthase inhibitor and a glycocorticosteroid on exhaled nitric oxide. Am J Respir Crit Care Med 1995; 152: 892-896.

15. Radomski MW, Palmer RMJ, Moncada S. Glucocorticoids inhibit the expression of an inducible, but not the constitutive nitric oxide synthase in vascular endothelial cells. Proc Nat Acad Sci 1990; 87: 10043-10047.

16. Kharitonov SA, Yates DH, Barnes PJ. Inhaled glycocorticoids decrease nitric oxide. Am J Respir Crit Care Med 1996; 153: 454-457. 
17. Kharitonov SA, Yates DH, Barnes PJ. Changes in the dose of inhaled steroid affect exhaled nitric oxide levels in asthmatic patients. Eur J Respir Dis 1996; 9: 196-201.

18. Massaro AF, Gaston B, Kita D, Fanta C, Stamler JS, Drazen JM. Expired nitric oxide levels during treatment of acute asthma. Am J Respir Crit Care Med 1995; 152: 800-803.

19. Martin U, Bryden K, Devoy M, Howarth P. Increased levels of exhaled nitric oxide during nasal and oral breathing in subjects with seasonal rhinitis. J Allergy Clin Immunol 1996; 97: 768-772.

20. Arnal JF, Didier Abram J, M'Rini C, Chcarlet JP, Serrano E, Bescombes JP. Nasal nitric oxide is increased in allergic rhinitis. Clin Expir Allergy 1997; 28: 358-363.

21. Kharitonov SA, Rajakulasingam K, O'Connor B, Durham $\mathrm{SR}$, Barnes P. Nasal nitric oxide is increased in patients with asthma and allergic rhinitis and may be modulated by nasal glucocorticoids. J Allergy Clin Immunol 1997; 9: 58-64.

22. Barnes PJ, Liew FY. Nitric oxide and asthmatic inflammation. Immunol Today 1995; 16: 128-130.

23. Kharitonov SA, Alving K, Barnes PJ. Exhaled and nasal nitric oxide measurements: recommendations. Eur Respir $J$ 1997; 10: 1683-1693.

24. Kharitonov SA, Barnes PJ. Nasal contribution to exhaled nitric oxide during exhalation against resistance or during breath holding. Thorax 1997; 52: 540-544.

25. Kharitonov SA, O'Connor BJ, Evans DJ, Barnes PJ. Allergen-induced late asthmatic reactions are associated with elevation of exhaled nitric oxide. Am J Respir Crit Care Med 1995; 151: 1894-1899.

26. Adisesh LA, Kharitonov SA, Yates DH, Snashell DC, Newman-Taylor AJ, Barnes PJ. Exhaled and nasal nitric oxide is increased in laboratory animal allergy. Clin Exp Allergy 1998; 28: 876-880.

27. Howarth PH, Wilson J, Djukanovic R, et al. Airway inflammation and atopic asthma: a comparative bron- choscopic investigation. Int Arch Allergy Appl Immunol 1991; 4: 266-269.

28. Jatakanon A, Lim S, Kharitonov SA, Chung KF, Barnes PJ. Correlation between exhaled nitric oxide, sputum eosinophils, and metacholine responsiveness in patients with mild asthma. Thorax 1998; 53: 91-95.

29. Robbins RA, Barnes PJ, Springall DR, et al. Expression of inducible nitric oxide synthase in human bronchial epithelial cells. Biochem Biophys Res Commun 1994; 203: 209-218.

30. Furukawa K, Harrison D, Saleh D, Shennib H, Chagnon F, Giaid A. Expression of nitric oxide synthase in human nasal mucosa. Am J Respir Crit Care Med 1996; 153: 847-850.

31. Humbert M, Durham SR, Ying S, et al. IL-4 and IL-5 mRNA and protein in bronchial biopsies from atopic and non-atopic asthma: evidence against "intrinsic" asthma being a distinct immunopathologiacal disease. $\mathrm{Am} \mathrm{J}$ Respir Crit Care Med 1996; 154: 1497-1504.

32. Humbert M, Ying S, Corrigan C, et al. Bronchial mucosal expression of the genes encoding chemokines Rantes and MCP-3 in symptomatic atopic and non-atopic asthmatics: relationship to the eosinophil-active cytokines interleukin-5, granulocyte macrophage-colony-stimulating factor, and IL-3. Am J Respir Cell Moll Biol 1997; 16: 1-8.

33. Walker C, Bode E, Boer L, Hansell TT, Blaser K, Virchow JC. Allergic and nonallergic asthma have distinct patterns of T-cell activation and cytokine production in peripheral blood and BAL. Am Rev Respir Dis 1992; 146: 109-115.

34. Folkard SG, Westwick J, Millar AB. Production of interleukin-8, Rantes and MCP-1 in intrinsic and extrinsic asthmatics. Eur Respir J 1997; 10: 2097-2104.

35. Tang C, Rolland LM, Ward C, Quan B, Walters EH. IL-5 production by bronchoalveolar lavage and peripheral blood mononuclear cells in asthma and atopy. Eur Respir $J$ 1997; 10: 624-632. 